\title{
Sutureless closure for the management of gastroschisis
}

\author{
Modupeola Diyaolu, Lauren S. Wood, Matias Bruzoni \\ Division of Pediatric Surgery, Lucile Packard Children's Hospital at Stanford University, Stanford, CA, USA \\ Contributions: (I) Conception and design: M Bruzoni; (II) Administrative support: M Bruzoni; (III) Provision of study materials or patients: All \\ authors; (IV) Collection and assembly of data: All authors; (V) Data analysis and interpretation: All authors; (VI) Manuscript writing: All authors; (VII) \\ Final approval of manuscript: All authors. \\ Correspondence to: Matias Bruzoni, MD. Division of Pediatric Surgery, Lucile Packard Children's Hospital at Stanford University, 300 Pasteur Drive, \\ Alway Building M116, MC 5733, Stanford, CA 94305, USA. Email: mbruzoni@stanfordchildrens.org.
}

\begin{abstract}
Gastroschisis is a common congenital anomaly in which the midgut fails to return to the abdominal cavity resulting in exposed intestines, which are not covered by a membrane in a neonate. The incidence of gastroschisis has been increasing worldwide resulting in an evolving medical and surgical management. Gastroschisis can be either simple or complicated. Complicated gastroschisis occurs when gastroschisis is associated with gastrointestinal conditions such as intestinal atresia, volvulus, stenosis or perforation. In this instance, the mortality and morbidity of patients significantly increases. Initial management of gastroschisis requires a multi-modal, interdisciplinary approach in order to successfully care for a neonate. Patients should be managed in a neonatal intensive care unit under the care of intensivists, respiratory therapists and pediatric surgeons. Temperature regulation, hydration and protection of the bowel are of the utmost priorities. Surgical management of gastroschisis focuses on reduction of the bowel and closure of the abdominal wall defect. Initially, the defect was closed primarily with suture, however, more recently, a sutureless closure has become prevalent. This, in conjunction with use of a silo, has led to a shift from the operating room and general anesthesia to the bedside. This article aims to discuss the presentation, diagnosis and management of gastroschisis
\end{abstract}

Keywords: Abdominal wound closure techniques; congenital abnormalities; gastroschisis; sutureless surgical procedure

Received: 16 April 2020; Accepted: 22 June 2020; Published: 25 July 2021.

doi: $10.21037 /$ tgh-20-185

View this article at: http://dx.doi.org/10.21037/tgh-20-185

\section{Introduction and epidemiology}

Gastroschisis is the most common congenital abdominal wall defect with an incidence of 3 to 9 cases per 10,000 live births that is increasing worldwide (1-9). Males are predominantly more affected than females (1). At 4 weeks of gestation the abdominal wall forms and during the $6^{\text {th }}$ week the midgut herniates into the umbilical cord due to rapid intestinal and liver growth (2). By the $10^{\text {th }}$ week, the midgut is supposed to return to the abdominal cavity. Gastroschisis occurs when the abdominal organs fail to return to the abdominal cavity. Risk factors for gastroschisis include young maternal age, smoking and infection $(8,10)$. There are many theories about the etiology of gastroschisis including vascular injury, abnormalities of ventral wall folding, and failure of the yolk sac to insert, however, no one theory has been verified $(2,4,9)$. The ventral defect associated with gastroschisis is less than $4 \mathrm{~cm}$ in diameter and there is no membrane covering the intestines (Figure 1). It is typically located to the right of the umbilical cord and usually only contains the midgut with the stomach and possibly gonads and distal colon $(1,8)$. Since the intestines are exposed to the uterine environment, the bowel can be thickened, matted, edematous and covered with a fibrinous peel, however, this can also occur postnatally when the bowel is exposed to the outside environment $(1,2)$. Neonates who have gastroschisis are more likely to be premature, 


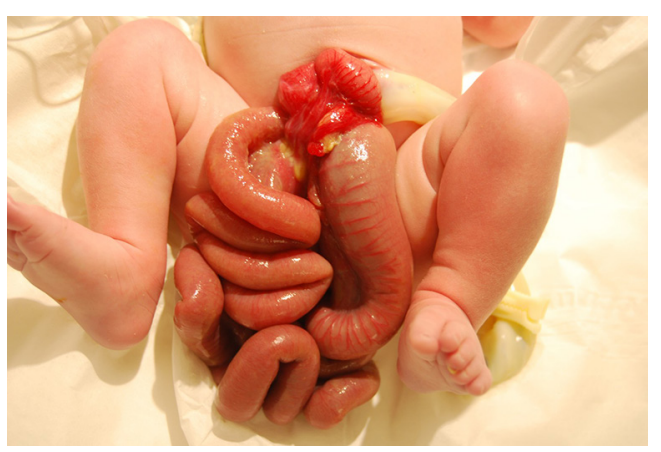

Figure 1 Newborn after immediate delivery with gastroschisis.

have respiratory complications, and be small for gestational age $(1,2)$.

\section{Complicated and uncomplicated gastroschisis}

Gastroschisis can be categorized into complicated and uncomplicated. Complicated gastroschisis is gastroschisis associated with a gastrointestinal condition such as atresia, perforation, stenosis, volvulus, or necrosis whereas simple or uncomplicated gastroschisis is not associated with these pathologies $(1,5,6,11,12)$. In addition, complicated gastroschisis is associated with increased morbidity and mortality when compared to uncomplicated gastroschisis $(1,4-7,11)$. Molik et al. found that neonates who presented with complicated gastroschisis had more days on mechanical ventilation, an extended period of adynamic ileus, longer hospitalizations, and a longer time delay before tolerating full enteral feeds (5). Arnold et al. experienced similar results as well as noting increased gastrointestinal, respiratory and infectious complications (11). Studies have shown that bowel dilatation on ultrasound is predictive of complicated gastroschisis $(6,7,13)$.

\section{Diagnosis}

The diagnosis of gastroschisis occurs via ultrasound typically in the second trimester $(2,8,13)$. Due to the risk of intrauterine growth retardation, it is recommended that all fetuses with gastroschisis be monitored with serial growth ultrasounds (13). In addition, in fetuses where there is no other indications for earlier evaluation, at $32-34$ weeks biweekly antepartum fetal heart rate testing is conducted (13). The optimal timing for delivery is still debated. Current theories suggest that prolonged bowel exposure to amniotic fluid is associated with hazardous effects on the developing bowel and early delivery may improve neonatal gut function $(9,14,15)$. Other studies show no difference between neonates born preterm ( $<37$ weeks) and 38 weeks or longer $(13,16,17)$. A large, multi-institutional, retrospective cohort study by Cain $e t$ al. demonstrated that as gestational age increased, there was a decreased length of stay and lower inpatient medical cost (9). In addition, neonates born at 37-38 weeks had decreased rates of jaundice and respiratory distress syndrome $(9,13)$. More recently, Carnaghan et al. demonstrated that neonates born electively before 37 weeks were associated with an increased incidence of neonatal sepsis and prolonged length of stay while Shamshirsaz et al. showed a significant increase in the rate of late-onset neonatal sepsis in neonates born at 34 weeks gestation (13-15). On the other hand, expectant management to full term has been associated with increased risk of bowel damage, neonatal sepsis, and death (13). Currently, the standard of care is for elective delivery at $37-38$ weeks $(13,14)$.

\section{Delivery method for gastroschisis patients}

While early studies suggested that cesarean (C-section) deliveries showed some benefit on outcomes, subsequent studies have showed that there are no increased risks of complications such as ischemic bowel, small bowel obstruction, or necrotizing enterocolitis with vaginal delivery $(7,10,13,18)$. Given the risks of $\mathrm{C}$-section, it is not recommended to plan a C-section specifically due to gastroschisis, however, expectant mothers can deliver via C-section or vaginal birth based on fetal well-being $(8,13,19)$. Ultimately, the patient and provider team coordinate to determine the method of delivery. While some elect to undergo spontaneous labor, other providers arrange for elective induction at 38 weeks of gestation $(20,21)$.

\section{Management of gastroschisis}

All gastroschisis patients should be managed in a neonatal intensive care unit under the close guidance of neonatal intensivists, respiratory therapists, and pediatric surgeons. Initial management of gastroschisis includes bowel protection with a translucent bag, temperature regulation and homeostasis, and reduction of evaporative losses $(1,19,22,23)$ (Figure 2). An initial examination of the intestines is required to rule out obvious findings like atresia or volvulus. An orogastric tube is placed for proximal decompression (24). Intravenous access is 
obtained for fluid resuscitation with a peripherally inserted central catheter placed for eventual initiation of total parental nutrition (21). While some institutions routinely place neonates on mechanical intubation, others elect to maintain spontaneous ventilation whenever possible $(10,19,21,23-25)$.

Surgical repair of gastroschisis can be approached through either a primary or a delayed repair. Sandler et al.

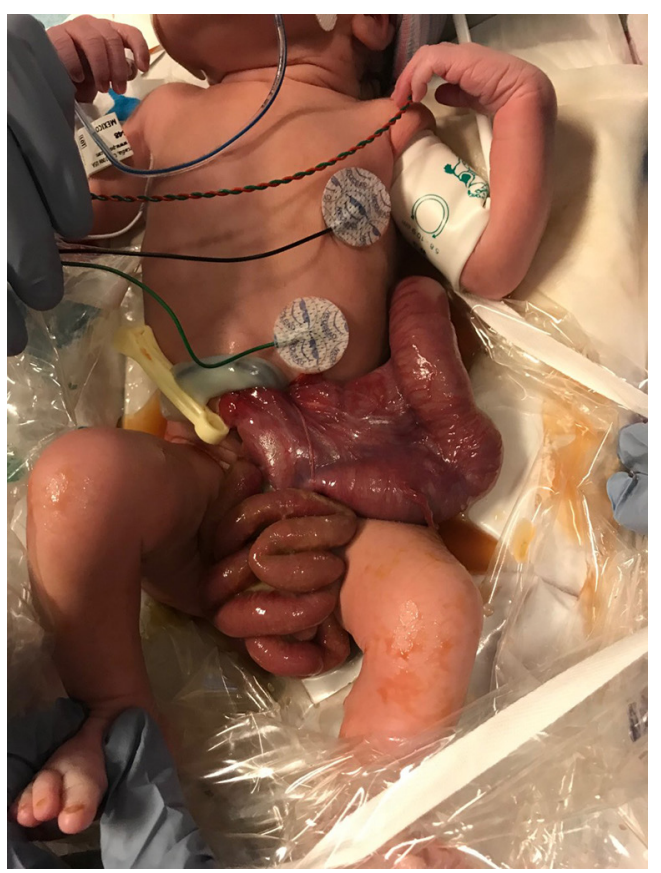

Figure 2 Immediate management of gastroschisis included bowel protection and temperature regulation. After delivery, neonates are placed into a translucent bag up to the axilla. pioneered the use of the sutureless technique which can be used in primary or delayed repair of gastroschisis (26). In a primary repair, the bowel is reduced, ideally in its anatomic location, followed by placement of the remaining umbilical cord over the defect and the application of an occlusive dressing such as Tegaderm $(19,22,24,26)$ (Figure 3). Distal decompression of the colon can sometimes reduce the size of the bowel and increase the chances of primary reduction (Figure 4). Given that this approach can be performed at bedside without the use of general anesthesia and sometimes without mechanical ventilation, the sutureless technique has become a popular method for surgical management of gastroschisis over the past decade (23). Alternatively, when the surgeon is unable to reduce the abdominal contents, a delayed repair can be performed in which the intestines are placed in a silastic silo and gradually reduced into the abdominal cavity $(21,23-25)$. Once the reduction is complete, the sutureless method can then be applied by placing a Mepilex/Mepitel pad and Tegaderm dressing over the abdominal defect (24) (Figure 5). Dressings are left in place and replaced every 4-5 days until epithelization occurs after which petroleum ointment and a light gauze dressing is utilized. Delayed repair of gastroschisis is often utilized when the bowel is thickened or dilated and reduction of the intestines causes significant respiratory compromise and/or abdominal compartment syndrome.

\section{Outcomes of gastroschisis sutureless closure methods}

Challenges exist in associating outcomes with method of closure given the relative rarity of this disease and the difficulty with adequately powering the study and
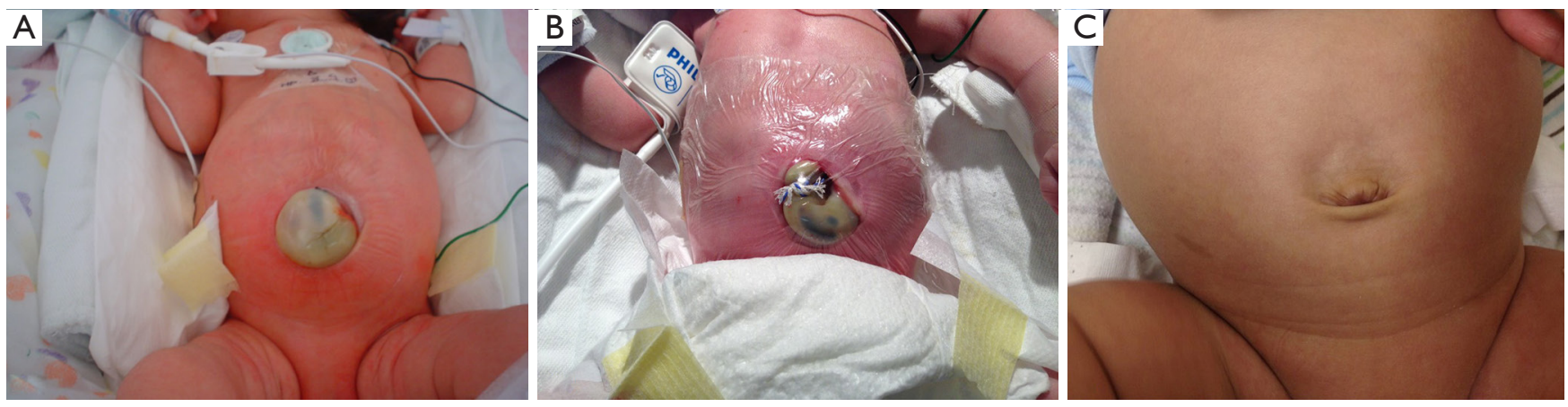

Figure 3 Reduction of gastroschisis. (A,B) Immediate reduction of the bowel can be accomplished at beside in the NICU. The umbilical cord is used to cover the defect after which an occlusive dressing such as Tegederm is used; (C) final result after complete healing of gastroschisis repair. 
subsequent subgroup analysis. Most analyses compare sutureless versus sutured repair involving simple gastroschisis and evidence is typically low-grade. However, since sutureless closure has been in practice, studies related to outcomes of gastroschisis sutureless closure frequently analyze time on ventilator, time to reach full enteral feeds (or other related nutritional goals), length of stay, and other complications associated with sutureless closure.

\section{Mortality}

Overall mortality of patients with gastroschisis undergoing sutureless versus sutured closure is reported to be comparable between the two groups $(27,28)$.

\section{Time on ventilator}

Sutureless closure of gastroschisis has been found to be associated with shorter time on the ventilator. As compared to patients undergoing fascial closure, those who had sutureless closure spent at least one day fewer on the

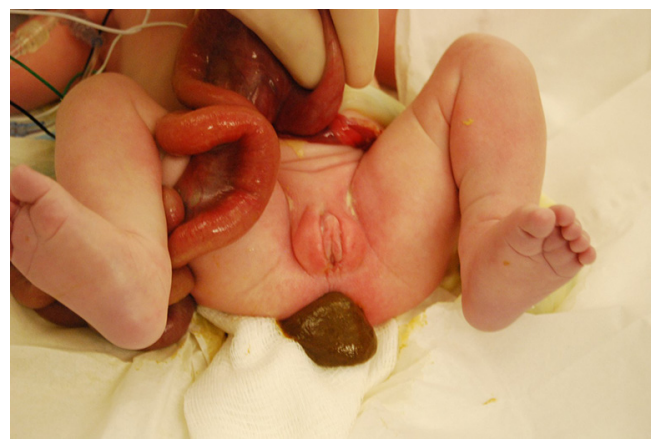

Figure 4 Expression of meconium during reduction of gastroschisis to aid bowel decompression and reduction. ventilator (3,28-31). A prospective randomized control trial demonstrated a similar finding, although the difference was not significant (32). A subgroup analysis of primary sutured versus sutureless closure suggested that while days on the ventilator was not significantly different, there was a significantly higher amount of patients requiring a ventilator in those who underwent primary sutured repair (84\% vs. 46\%) (33). A retrospective case control study suggested that use of silo reduction independently increased time to extubation (24).

\section{Time to nutritional goals}

Patients reaching nutritional goals-time to reach full enteral feeds time requiring total parenteral nutrition, time to initiating feeds-has been shown to be comparable between sutured and sutureless closure. The amount of time patients were given TPN prior to replacement by enteral feeds was comparable between sutureless (or flap) closure and sutured (or fascial) closure in both a systematic review and meta-analysis, and more recent retrospective case control studies $(3,28,29)$. Subgroup analysis of primary sutured versus sutureless closure suggested shorter total time on TPN for primary sutured closure (18 vs. 24 days); comparison of delayed sutured versus sutureless closure revealed no difference, a parallel finding to the overall analysis between cohorts (33).

Time to reach full enteral feeds appears to be comparable between groups, although variability has been reported. A randomized control trial showed longer time for the sutureless cohort to reach full enteral feeds (45 vs. 28 days), although many of these patients required silo reduction which resulted in bigger defects, which other authors have reported as a risk factor for longer time to achieve enteral autonomy $(24,32,34)$. The most recent retrospective
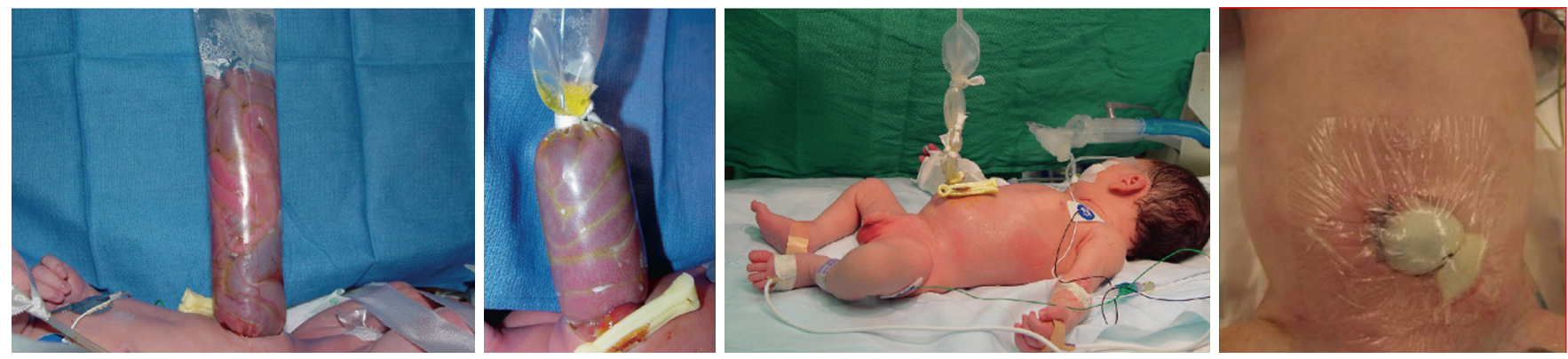

Figure 5 When immediate reduction cannot be accomplished a silo can be placed and the intestines can be gradually reduced into the abdominal cavity. 

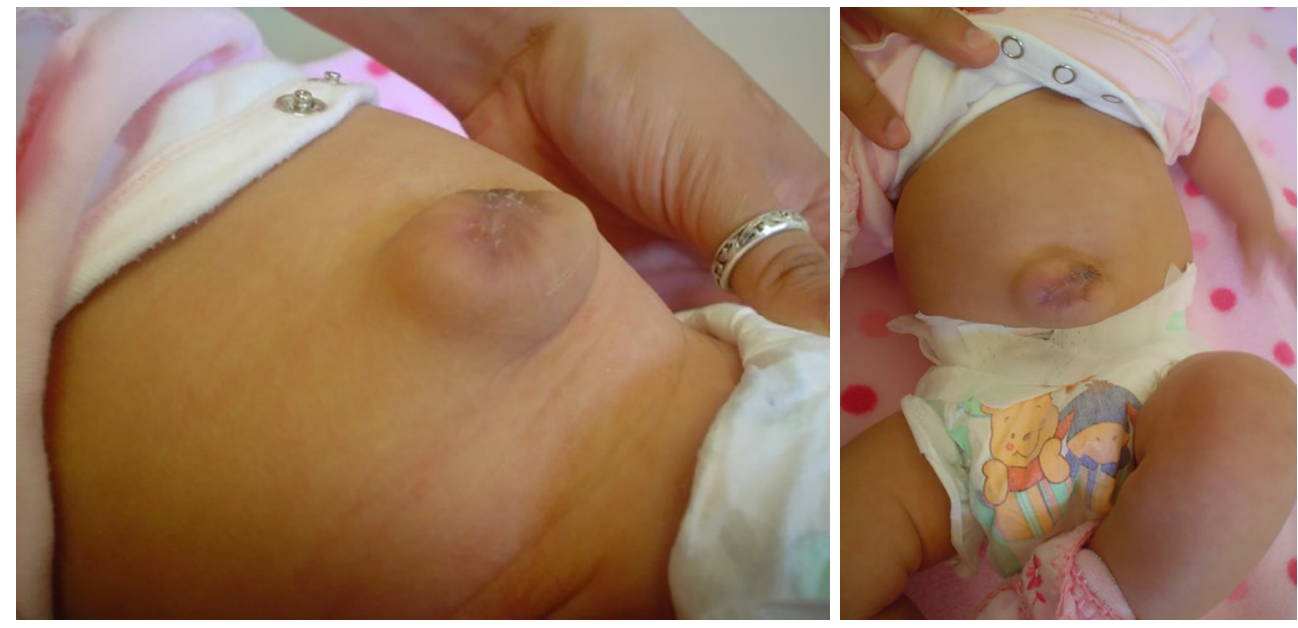

Figure 6 Umbilical hernia after sutureless gastroschisis repair.

review from the Midwest Pediatric Surgery Consortium also appeared to have a trend towards longer time to reach full feeds in a sutureless group, but this difference was not significant (33).

\section{Time to discharge from neonatal intensive care unit}

Most studies conclude that sutureless closure does not have a significant difference in length of stay in the NICU compared to sutured closure $(3,24,28,30,31)$. While sutureless closure may contribute to a longer length of stay seen in a randomized control trial (49 vs. 31 days), the authors believed this could be due to a non-standardized length of time for patients to remain with a silo in place (32). Subgroup analysis for a retrospective cohort review showed that there was a similar length of stay between patients that had a silo in place and method of closure (36 days sutureless vs. 33.5 days sutured), but there was no analysis between patients with silo and without silo, as it could have served as a confounding factor (33).

\section{Rate of complications}

\section{Abdominal compartment syndrome}

Abdominal compartment syndrome is a feared complication of gastroschisis reduction and closure. The actual incidence of compartment syndrome is unknown and appears to be quite rare, but delayed closure is believed to reduce the risk of compartment syndrome (35-37). A national observational study from the United Kingdom demonstrated two incidents of abdominal compartment syndrome out of 381 cases (12). Studies have described this complication in both methods of closure (31-34).

\section{Wound complications}

While recent retrospective cohort reviews found no difference in wound infections between sutured and sutureless closure, meta-analyses suggest that sutured closure may put patients at a higher risk of developing superficial or deep tissue infections $(3,27,28,31,33)$. Two meta-analyses found odds ratios of 0.24 and 0.40 for wound infections after plastic closure (or sutureless closure); subgroup analysis after silo placement also favored the sutureless closure cohort $(27,28)$. Bruzoni et al. in the randomized control trial also found an increased incidence in wound infection in sutured versus sutureless closure patients (55\% vs. $21 \%)$. After closure, patients with sutured closure were found to be more likely to be on antibiotics, which may falsely lower the wound infection rate (33).

\section{Umbilical hernias requiring operative repair}

The incidence of umbilical hernias requiring operative repair appears to be quite variable (Figure 6). Over a 10year period, a retrospective review found that sutureless closure was more likely to result in an umbilical hernia requiring reoperation at a median age of 13 months (3). A meta-analysis incorporating 12 studies found that while sutureless closure was more likely to result in an umbilical hernia, analyzed studies suggested that sutured repair was more likely to require reoperation ( $41 \%$ vs. $19 \%$ ); however, the length of follow up was quite variable across all studies analyzed (28). 


\section{Conclusions}

In conclusion, gastroschisis is a congenital gastrointestinal disoder that has varying degrees of presentations and when complicated increases the morbidy and mortality of patients. Management of gastroschisis includes temperature regulation, bowel protection, hydration and should be a coordinated effort between neonatal intensivists, respiratory therapists and the pediatric surgery team. Closure of the gastroschisis defect has evolved to a bedside procedure using a sutureless method in which the bowel is reduced, the umbilical cord is used as a covering and then a dressing is applied. This method has limited neonatal exposure to general anesthesia and decreased the need for mechanical ventilation.

While abdominal compartment syndrome can occur, it is rare and can be managed by placing the bowel in a silo, followed by a gradual reduction of the intestines and then utilization of the sutureless method. When comparing sutureless and sutured methods, there is no significance difference in terms of wound infection, time to enteral feeding or time to discharge from the NICU. After the patient has fully healed, cases of umbilical hernias are reported, however, the need for operative intervention varies. Overall, the sutureless method is a successful and viable method for the management of gastroschisis.

\section{Acknowledgments}

Funding: None.

\section{Footnote}

Provenance and Peer Review: This article was commissioned by the Guest Editors (Eduardo Perez, Samir Pandya, and Matthew S. Clifton) for the series "Current Topics in Pediatric General Surgery" published in Translational Gastroenterology and Hepatology. The article has undergone external peer review.

Conflicts of Interest: All authors have completed the ICMJE uniform disclosure form (available at http://dx.doi. org/10.21037/tgh-20-185). The series "Current Topics in Pediatric General Surgery" was commissioned by the editorial office without any funding or sponsorship. The authors have no other conflicts of interest to declare.

Ethical Statement: The authors are accountable for all aspects of the work in ensuring that questions related to the accuracy or integrity of any part of the work are appropriately investigated and resolved.

Open Access Statement: This is an Open Access article distributed in accordance with the Creative Commons Attribution-NonCommercial-NoDerivs 4.0 International License (CC BY-NC-ND 4.0), which permits the noncommercial replication and distribution of the article with the strict proviso that no changes or edits are made and the original work is properly cited (including links to both the formal publication through the relevant DOI and the license). See: https://creativecommons.org/licenses/by-nc-nd/4.0/.

\section{References}

1. Klein MD. Congenital defects of the abdominal wall. In: Coran AG, Caldamone A, Adzick NS, et al. editors. Pediatric surgery. 7th ed. Philadelphia: Elsevier Saunders, 2012:973-84.

2. Islam S. Congenital abdominal wall defects: gastroschisis and omphalocele. In: Holcomb GW, Murphy JP, St. Peter SD, et al. editors. Holcomb and Ashcraft's pediatric surgery. 7th ed. Philadelphia: Elsevier Inc., 2020:763-79.

3. Witt RG, Zobel M, Padilla B, et al. Evaluation of clinical outcomes of sutureless vs sutured closure techniques in gastroschisis repair. JAMA Surgery 2019;154:33-9.

4. Bergholz R, Boettcher M, Reinshagen K, et al. Complex gastroschisis is a different entity to simple gastroschisis affecting morbidity and mortality - a systematic review and meta-analysis. J Pediatr Surg 2014;49:1527-32.

5. Molik KA, Gingalewski CA, West KW, et al. Gastroschisis: a plea for risk categorization. J Pediatr Surg 2001;36:51-5.

6. Kuleva M, Khen-Dunlop N, Dumez Y, et al. Is complex gastroschisis predictable by prenatal ultrasound? BJOG 2012;119:102-9.

7. Robertson JA, Kimble RM, Stockton K, et al. Antenatal ultrasound features in fetuses with gastroschisis and its prediction in neonatal outcome. Aust N Z J Obstet Gynaecol 2017;57:52-6.

8. Friedman AM, Ananth C V, Siddiq Z, et al. Gastroschisis: epidemiology and mode of delivery, 2005-2013. Am J Obstet Gynecol 2016;215:348.e1-9.

9. Cain MA, Salemi JL, Tanner JP, et al. Perinatal outcomes and hospital costs in gastroschisis based on gestational age at delivery. Obstet Gynecol 2014;124:543-50.

10. Fullerton BS, Velazco CS, Sparks EA, et al. Contemporary outcomes of infants with gastroschisis in north america: a 
multicenter cohort study. J Pediatr 2017;188:192-7.e6.

11. Arnold MA, Chang DC, Nabaweesi R, et al. Risk stratification of 4344 patients with gastroschisis into simple and complex categories. J Pediatr Surg 2007;42:1520-5.

12. Owen A, Marven S, Johnson P, et al. Gastroschisis: a national cohort study to describe contemporary surgical strategies and outcomes. J Pediatr Surg 2010;45:1808-16.

13. Oakes MC, Porto M, Chung JH. Advances in prenatal and perinatal diagnosis and management of gastroschisis. Semin Pediatr Surg 2018;27:289-99.

14. Carnaghan H, Baud D, Lapidus-Krol E, et al. Effect of gestational age at birth on neonatal outcomes in gastroschisis. J Pediatr Surg 2016;51:734-8.

15. Shamshirsaz AA, Lee TC, Hair AB, et al. Elective delivery at 34 weeks vs routine obstetric care in fetal gastroschisis: randomized controlled trial. Ultrasound Obstet Gynecol 2020;55:15-9.

16. Logghe HL, Mason GC, Thornton JG, et al. A randomized controlled trial of elective preterm delivery of fetuses with gastroschisis. J Pediatr Surg 2005;40:1726-31.

17. Al-Kaff A, Macdonald SC, Kent N, et al. Delivery planning for pregnancies with gastroschisis: findings from a prospective national registry. Am J Obstet Gynecol 2015;213:557.e1-8.

18. Segel SY, Marder SJ, Parry S, et al. Fetal abdominal wall defects and mode of delivery: A systematic review. Obstet Gynecol 2001;98:867-73.

19. Petrosyan M, Sandler AD. Closure methods in gastroschisis. Semin Pediatr Surg 2018;27:304-8.

20. Manson J, Ameh E, Canvassar N, et al. Gastroschisis: a multi-centre comparison of management and outcome. Afr J Paediatr Surg 2012;9:17-21.

21. Haddock C, Ghalgya A, Maawali A, et al. Impact of multidisciplinary standardization of care for gastroschisis: treatment, outcomes, and cost. J Pediatr Surg 2018;53:892-7.

22. Orion KC, Krein M, Liao J, et al. Outcomes of plastic closure in gastroschisis. Surgery 2011;150:177-85.

23. Chesley PM, Ledbetter DJ, Meehan JJ, et al. Contemporary trends in the use of primary repair for gastroschisis in surgical infants. Am J Surg 2015;209:9015; discussion 905-6.

24. Riboh J, Abrajano CT, Garber K, et al. Outcomes of sutureless gastroschisis closure. J Pediatr Surg 2009;44:1947-51.

25. Pastor AC, Phillips JD, Fenton SJ, et al. Routine use of a SILASTIC spring-loaded silo for infants with gastroschisis: a multicenter randomized controlled trial. J Pediatr Surg 2008;43:1807-12.
26. Sandler A, Lawrence J, Meehan J, et al. A "plastic" sutureless abdominal wall closure in gastroschisis. J Pediatr Surg 2004;39:738-41.

27. Miyake H, Seo S, O'Connell JS, et al. Safety and usefulness of plastic closure in infants with gastroschisis: a systematic review and meta-analysis. Pediatr Surg Int 2019;35:107-16.

28. Youssef F, Gorgy A, Arbash G, et al. Flap versus fascial closure for gastroschisis: A systematic review and metaanalysis. J Pediatr Surg 2016;51:718-25.

29. Zajac A, Bogusz B, Soltysiak P, et al. Cosmetic outcomes of sutureless closure in gastroschisis. Eur J Pediatr Surg 2016;26:537-41.

30. Pet GE, Stark RA, Meehan JJ, et al. Outcomes of bedside sutureless umbilical closure without endotracheal intubation for gastroschisis repair in surgical infants. Am J Surg 2017;213:958-62.

31. Emami CN, Youssef F, Baird RJ, et al. A risk-stratified comparison of fascial versus flap closure techniques on the early outcomes of infants with gastroschisis. J Pediatr Surg 2015;50:102-6.

32. Bruzoni M, Jaramillo JD, Dunlap JL, et al. Sutureless vs sutured gastroschisis closure: a prospective randomized controlled trial. J Am Coll Surg 2017;224:1091-6.e1.

33. Fraser JD, Deans KJ, Fallat ME, et al. Sutureless vs sutured abdominal wall closure for gastroschisis: operative characteristics and early outcomes from the Midwest Pediatric Surgery Consortium. J Pediatr Surg 2020;55:2284-8.

34. Choi WW, McBride CA, Bourke C, et al. Longterm review of sutureless ward reduction in neonates with gastroschisis in the neonatal unit. J Pediatr Surg 2012;47:1516-20.

35. Tsai MH, Huang HR, Chu SM, et al. Clinical features of newborns with gastroschisis and outcomes of different initial interventions: primary closure versus staged repair. Pediatr Neonatol 2010;51:320-5.

36. Kidd JN Jr, Jackson RJ, Smith SD, et al. Evolution of staged versus primary closure of gastroschisis. Ann Surg 2003;237:759-65.

37. Minkes RK, Langer JC, Mazziotti MV, et al. Routine insertion of a silastic spring-loaded silo for infants with gastroschisis. J Pediatr Surg 2000;35:843-6.

doi: $10.21037 /$ tgh-20-185

Cite this article as: Diyaolu M, Wood LS, Bruzoni M. Sutureless closure for the management of gastroschisis. Transl Gastroenterol Hepatol 2021;6:31. 